\title{
Food Simulating Organic Solvents for Evaluating Crosslink Density of Bulk Fill Composite Resin
}

\author{
Neveen M. Ayad, ${ }^{1}$ Hala A. Bahgat, ${ }^{1}$ Eman Hussain Al Kaba, \\ and Maryam Hussain Buholayka ${ }^{2}$ \\ ${ }^{1}$ Restorative Dental Sciences Department, College of Dentistry, University of Dammam, Dammam, Saudi Arabia \\ ${ }^{2}$ College of Dentistry, University of Dammam, Dammam, Saudi Arabia
}

Correspondence should be addressed to Neveen M. Ayad; nmhanna@uod.edu.sa

Received 12 December 2016; Revised 11 March 2017; Accepted 29 March 2017; Published 12 April 2017

Academic Editor: Carlos A. Munoz-Viveros

Copyright (C) 2017 Neveen M. Ayad et al. This is an open access article distributed under the Creative Commons Attribution License, which permits unrestricted use, distribution, and reproduction in any medium, provided the original work is properly cited.

\begin{abstract}
Objectives. To evaluate crosslink densities of two bulk fill composite resins and determine if the used Food Simulating Organic Solvent (FSOS) affected them. Methods. Forty specimens were prepared from SureFill and SonicFill bulk fill composite resins, 20 each. All specimens were stored dry for $24 \mathrm{~h}$. Each group was divided into 2 subgroups: stored in ethanol (E) $75 \%$ or in methyl ethyl ketone (MEK) 100\% for $24 \mathrm{~h}$. Crosslink density was evaluated by calculating the difference between the Vickers hardness numbers of the specimens stored dry and after their storage in FSOS. The data were statistically analyzed using $t$-test. Results. The means of crosslink density in E and MEK were $6.99 \%$ and $9.44 \%$ for SureFill and $10.54 \%$ and $11.92 \%$ for SonicFill, respectively. $t$-test displayed significant differences between crosslink densities of SureFill and SonicFill: $(P<0.0001)$ in $\mathrm{E}$ and $(P=0.02)$ in MEK and between crosslink densities of SureFill in E and MEK $(P=0.02)$. Conclusions. Crosslink density of bulk fill composite resin can be evaluated using E or MEK. SureFill has higher crosslink density than SonicFill in both E and MEK.
\end{abstract}

\section{Introduction}

The oral cavity contains a diversity of chemical components from food and saliva including alkalis, acids, salts, and alcohol that may be absorbed by composite resin resulting in their degradation [1-3]. Water which is a major constituent of human saliva has a proven influence on composite resin [4-6]. Ethanol (E) is an organic solvent that is considered a food simulant by the US Food and Drug Administration (FDA) [7]. Methyl ethyl ketone (MEK) which naturally exists in various types of fruits, meat, vegetables, and yogurt has also been approved by the FDA as a food additive and is considered a food simulating liquid [8].

To evaluate the softening effect of the oral environment on composite resin, the solubility parameter is of extreme importance. It provides a numerical value through which the level of interaction between materials can be expected [4-9].
Greater softening effects are expected when the resin matrix and the solvent have closely matching solubility parameters [10-12].

Both ethanol and methyl ethyl ketone FSOS have solubility parameters closely matching that of Bis-GMA (the most commonly used monomer in composite resin) [9]. Previous studies relied on ethanol, either in its absolute form or diluted $75 \% \mathrm{E} /$ water [13], to evaluate the crosslink density of the polymer network.

Bulk fill composite resin is widely spreading amongst dentists due to its simple application technique. It displayed adequate light-curing to about $5 \mathrm{~mm}$ depth by measuring degree of conversion, compressive strength, and top/bottom hardness [14]. However, its durability during service can be affected not only by how efficient its curing was which directly affects the extent of monomer transformation into polymer, but also to which extent the polymer network 
is crosslinked. The degree of conversion is the number of ethylene double carbon bonds that are converted into single bonds of the composite resin to obtain the optimal chemical-physicomechanical behavior. However, polymers with comparable degree of conversion may have dissimilar crosslink densities due to variances in the linearity/branching of the polymer chains [15].

Recent studies have proved that MEK has stronger softening effect on bulk fill composite resin than E [2]. Thus the authors hypothesize that MEK could be an efficient alternative for $\mathrm{E}$ in assessment of crosslink density of bulk fill composite resin.

\section{Materials and Methods}

Two bulk fill composite resins were used in this investigation (Table 1).

2.1. Specimens' Preparation. Twenty specimens were prepared from each composite resin; 10 were kept in $\mathrm{E}$ and the other 10 in MEK. The bulk fill composite resin was packed into a cylindrical Teflon mold of $2.5 \mathrm{~mm}$ inner diameter and $5 \mathrm{~mm}$ height placed on a glass slab. The mold was packed with composite resin as a single layer. SonicFill was applied by sonic activated hand-piece, as recommended by the manufacturer. Light-irradiation was performed for $20 \mathrm{~s}$ on the top of the specimens using a light emitting diode curing unit $\left(1200 \mathrm{~mW} / \mathrm{cm}^{2}\right.$, Bluephase 20i, Ivoclar Vivadent, Schaan, Liechtenstein). The top surfaces of all specimens were marked. Then the specimens were kept dry for $24 \mathrm{~h}$ at room temperature $\left(23 \pm 1^{\circ} \mathrm{C}\right)$ before testing.

2.2. Evaluation of Crosslink Density. The evaluation of crosslink density was determined indirectly by calculating the difference between the top Vickers hardness numbers of the specimens stored dry for $24 \mathrm{~h}$ and after their storage in FSOS [15].

2.2.1. Measurement of Vickers Hardness Number of the Specimens Stored Dry for $24 \mathrm{~h}$. Three indentations (load: $50 \mathrm{~g}$; dwell time: 15 seconds) were performed on the top surface of each specimen using Vickers's hardness tester (Micromet 6049 , Buehler, Illinois, USA). The mean of these three individual measurements was considered as the Vickers hardness number of the overall surface.

\subsubsection{Measurement of Vickers Hardness Number after Speci-} mens' Storage in FSOS. The specimens were stored individually in $10 \mathrm{~mL}$ of either $75 \%$ ethanol or $100 \%$ methyl ethyl ketone at $37 \pm 1^{\circ} \mathrm{C}$ according to their groups for $24 \mathrm{~h}$. A remeasurement of the Vickers hardness number of the top surface was recorded for the specimens removed from the respective FSOS. The crosslink density was obtained by using the formula [15]:

$$
\begin{aligned}
& \text { Crosslink density } \\
& =\frac{\text { [Vickers hardness number after storage in FSOS - Vickers hardness number after } 24 \mathrm{~h} \text { of dry storage] }}{100} .
\end{aligned}
$$

2.3. Statistical Analysis. Statistical data were analyzed by using SPSS-20.0 (IBM product-USA). Mean and standard deviation were calculated for the Vickers hardness number of all subgroups. Two way ANOVA was used to assess the overall effect of material and solvent on the crosslink density and the estimated means were compared using Bonferroni adjustment. $t$-test was used to assess differences in crosslink density after using different solvents in each material and between the two materials after the use of each solvent.

\section{Results}

The mean Vickers hardness numbers of the tested bulk fill composite resins stored dry for $24 \mathrm{~h}$ and stored in $\mathrm{E}$ and MEK as well as the calculated crosslink densities are presented in Table 2. Two way ANOVA displayed a significant effect of the bulk fill composite resin and the Food Simulating Organic Solvent on the crosslink density. The estimated means were compared using Bonferroni adjustment. $t$-test displayed significant difference between the crosslink density of SureFill and SonicFill for each used FSOS. $t$-test also revealed significant difference between the crosslink densities measured for SureFill specimens stored in E and MEK.

\section{Discussion}

Crosslink density is an important indicator of the chemical stability of composite resin [12, 16]. A polymer with high crosslink density is characterized by tight network structure with improved packing density and minimized free vicinity of the entangled polymer chains. This restricts the diffusion of the solvent molecules in and out of the polymer structure and as a result decreases their plasticization impact [12]. Consequently, the magnitude of crosslink points in a resin structure dictates its mechanical performance. A limited crosslinked resin structure shows less stiffness, more rubbery behavior, and poor surface integrity [17]. Surface hardness is considered a key performance indicator of the service life of composite resin dental restorations [1]. Softening tests, that are based on evaluating the top hardness value of composite resin before and after its immersion in ethanol solution for $24 \mathrm{~h}$, have been used to assess crosslink density $[1,18]$ instead of performing complex differential scanning calorimetry tests [19]. The vulnerability of the polymer to softening can be clarified by the solvent capability of diffusion in the composite resin and bonding to the polymer chains replacing the 
TABLE 1: Technical specifications of the tested materials according to their manufacturers.

\begin{tabular}{lcc}
\hline Composite resin & $\begin{array}{c}\text { SonicFill } \\
\text { (Sculpt-able) }\end{array}$ & $\begin{array}{c}\text { SureFill } \\
\text { (Sculpt-able) }\end{array}$ \\
\hline Manufacturer & $\begin{array}{c}\text { Kerr Corporation, CA, USA/Kavo } \\
\text { Germany }\end{array}$ & Dentsply/Caulk (USA) \\
\hline Increment thickness $(\mathrm{mm})$ & $5 \mathrm{~mm}$ & $5 \mathrm{~mm}$ \\
\hline Monomer & Bis-GMA & Bis-GMA, \\
UDMA, & TEGDMA
\end{tabular}

TABLE 2: Mean hardness number and crosslink density of the tested bulk fill composite resins after dry storage, storage in $75 \%$ ethanol, and storage in $100 \%$ methyl ethyl ketone.

\begin{tabular}{|c|c|c|c|c|}
\hline Bulk fill composite resin & Dry storage & Storage in $75 \% \mathrm{E}$ & Storage in $100 \%$ MEK & $P$ value \\
\hline \multicolumn{5}{|l|}{ SureFill } \\
\hline Vickers hardness number (SD) & $82.4(2.4)$ & $76.6(2.1)$ & $74.6(1.7)$ & \\
\hline Crosslink density (SD) & - & $7.0(1.4)$ & $9.4(2.5)$ & $0.02^{*}$ \\
\hline \multicolumn{5}{|l|}{ SonicFill } \\
\hline Vickers hardness number (SD) & $99.0(1.3)$ & $88.5(1.6)$ & $87.2(1.8)$ & \\
\hline Crosslink density (SD) & - & $10.5(1.8)$ & $11.9(1.3)$ & 0.06 \\
\hline$P$ value $^{€}$ & & $<0.0001^{*}$ & $0.02^{*}$ & \\
\hline
\end{tabular}

SD: standard deviation.

${ }^{9} P$ value of $t$-test comparing differences after using solvents in each material.

${ }^{€} P$ value of $t$-test comparing the two materials when each solvent was used.

${ }^{*}$ Statistically significant difference at $P \leq 0.05$.

interchain secondary bonds. Thereby, the solvent jeopardizes the polymer chains entanglement and promotes dissolution of the residual monomer units. Such solvent, in the same time, cannot beat primary covalent crosslinks; thus the molecules of the polymer cannot be carried off into solution. The capability of a specific solvent to soften a material relies on their relative polarities [20,21]. Substances that have comparable polarities will be equally solvable, but dissimilar polarities will make solubility progressively challenging. So, what is crucial is not the absolute value of the solubility limit, but its proximity to or difference from that of another substance The solubility parameters of the applied organic solvents $\mathrm{E}$ and $\mathrm{MEK}\left(26.2 \delta / \mathrm{MPa}^{1 / 2}\right.$ and $19.3 \delta / \mathrm{MPa}^{1 / 2}$, resp.) are close to that of poly methyl methacrylate resin $\left(18.6 \delta / \mathrm{MPa}^{1 / 2}\right)$ [9]. In this study, two bulk fill composite resins have been investigated: the sculpt-able SureFill since 1990 s with an overall survival rate of $94.76 \%$ in $1-5$ years [22] and the relatively recent sculpt-able SonicFill 2010. Both are dimethacrylate composite resins that show closely matching solubility parameter to that of poly methyl methacrylate resin.

The hardness assessment of the two bulk fill composite resins was conducted to estimate the crosslink density resultant from storage in $\mathrm{E}$ and MEK. The results revealed that both solvents produced reduction in hardness of the investigated composite resins. Such reduction can be explained by the solvent-polymer interaction detailed earlier in this context. These results were also consistent with other studies that investigated the effects of organic solvents on composite resins $[5,15,23]$. However, the degradation was higher in MEK for both composite resins with significant value in SureFill. The same trend has been encountered during testing of viscoelastic stability, expressed by creep parameters, of different composite resins by Marghalani and Watts 2013 [5], the flexural properties of bulk fill composites by Marghalani 2015 [2], and finally the hardness and diametral tensile strength of bulk fill composites by Sunbul et al. 2016 [24]. Hence, this behavior could be considered an indication of the higher resemblance of the solubility parameters of MEK and the dimethacrylate monomer systems of the tested composite resins than in case of $\mathrm{E}$. Therefore the assumption that MEK would be an efficient alternative for $\mathrm{E}$ in assessment of crosslink density is accepted.

SureFill showed significant higher crosslink density than SonicFill where the former showed less decrease in Vickers hardness number after being stored in FSOS. It can be speculated that the polymeric network of SureFill consists 
of more crosslinked chains rather than the linear polymeric structure present in SonicFill. Such linear polymeric structure can encourage the diffusion of solvent inside as stated by Ferracane 2006 [12]. The degree of disintegration is apparently related to the interaction of the solvents with the constituent oligomers, which are the same in both investigated bulk fill composites except for UDMA in SureFill and BIS-EMA in SonicFill (Table 1).

The higher resistance of SureFill to softening could be attributed to the presence of UDMA. The latter is an aliphatic flexible oligomer owing to the presence of flexible urethane linkage instead of the stiff iso-propylidene-di-phenoxy center core present in both Bis-GMA and its analog Bis-EMA. This flexibility allowed free initial mobility of UDMA ensuring the close proximity of the radical species, thus creating multiple centers of polymer growth (crosslink centers). In addition, the opportunity of chain transfer reactions through the imino group should be responsible for more rapid rate of polymerization in SureFill, evident in network formation prior to diffusion-controlled propagation stage [25-27]. Hence, the faster polymerization reaction rate is usually accompanied by formation of a more branched and crosslinked polymer network $[1,11]$.

Goņalves et al. 2009 [28] and Cornelio et al. 2014 [29] attributed the higher degree of conversion, achieved in their tentative composite resin formulations when the content of Bis-EMA was increased, to the lower initial viscosity. But this lower viscosity seemed to slow down the rate of polymerization thus delaying the onset of autoacceleration, which is responsible for creating numerous foci of polymer growth (crosslink centers). Thus, a linear and less branched polymer network is obviously expected to be the final product in these experimental composite formulations.

Moreover, one should emphasize that the higher crosslink density of SureFill has overshadowed the relatively higher hydrophilic nature of its UDMA oligomer due to the presence of urethane group (-NHCOO-) when compared to BISEMA with its ether group (-O-) of lower hydrophilicity. This could be supported by the study of Pfeifer et al. 2009, who concluded that experimental composite resins composed of Bis-GMA : TEGDMA : UDMA offered the best compromise between degree of conversion from one side and flexural properties, fracture toughness, and susceptibility to ethanol degradation from the other side.

In addition to the impact of the monomers, the particulate filler also provides an essential part in defining the resistance to the plasticizing effect of organic solvents. An increase in the filler loading is most probably associated with higher resistance of the tested composite resins to degradation. Surprisingly, SonicFill displayed higher deterioration after conditioning in the organic solvents in spite of its relatively higher filler loading, Table 1 . On the other hand, SureFill features a specially designed interlocking particle technology that could present obstacle against the attack of food simulating organic softening agents [30]. Therefore, it seems that the pattern of the filler distribution, mainly short interfiller spacing, was responsible for slowing down the percolation effect of plasticizing agents on SureFill.

\section{Conclusion}

Within the limitation of this investigation, the following can be concluded:

(1) The crosslink density of dimethacrylate-based bulk fill composite resins can be evaluated using either ethanol or methyl ethyl ketone food simulating organic solvents with expected higher values for the latter.

(2) SureFill has higher crosslink density than SonicFill composite resin in both ethanol and methyl ethyl ketone food simulating organic solvents.

\section{Conflicts of Interest}

The authors declare that there are no conflicts of interest regarding the publication of this paper.

\section{Acknowledgments}

The authors thank Professor Dr. Maha Tantawy for her efforts in the statistical analysis of this study.

\section{References}

[1] E. Asmussen and A. Peutzfeldt, "Influence of pulse-delay curing on softening of polymer structures," Journal of Dental Research, vol. 80, no. 6, pp. 1570-1573, 2001.

[2] H. Y. Marghalani, "Effect of chemical solvents on flexural properties of bulk-fill composites," Dental Materials, vol. 31, supplement 1, pp. e15-e16, 2015.

[3] E. C. Kao, "Influence of food-simulating solvents on resin composites and glass-ionomer restorative cement," Dental Materials, vol. 5, no. 3, pp. 201-208, 1989.

[4] S.-Y. Lee, E. H. Greener, and H. J. Mueller, "Effect of food and oral simulating fluids on structure of adhesive composite systems," Journal of Dentistry, vol. 23, no. 1, pp. 27-35, 1995.

[5] H. Y. Marghalani and D. C. Watts, "Viscoelastic stability of resin-composites aged in food-simulating solvents," Dental Materials, vol. 29, no. 9, pp. 963-970, 2013.

[6] J. L. Ferracane, J. K. Hopkin, and J. R. Condon, "Properties of heat-treated composites after aging in water," Dental Materials, vol. 11, no. 5-6, pp. 354-358, 1995.

[7] J. L. Ferracane, H. X. Berge, and J. R. Condon, "In vitro aging of dental composites in water-effect of degree of conversion, filler volume, and filler/matrix coupling," Journal of Biomedical Materials Research, vol. 42, no. 3, pp. 465-472, 1998.

[8] Food and Drug Administration (FDA), Guidelines for Chemistry and Technology Requirements of Indirect Food Additive Petitions, Bureau of Foods, Department of Health, Education and Welfare, Washington, DC, USA, 1976.

[9] J. E. McKinney and W. Wu, "Chemical softening and wear of dental composites," Journal of Dental Research, vol. 64, no. 11, pp. 1326-1331, 1985.

[10] I. S. Medeiros, M. N. Gomes, A. D. Loguercio, and L. E. R. Filho, "Diametral tensile strength and Vickers hardness of a composite after storage in different solutions," Journal of Oral Science, vol. 49, no. 1, pp. 61-66, 2007. 
[11] W. Wu and J. McKinney, "Influence of chemicals on wear of dental composites," Journal of Dental Research, vol. 61, no. 10, pp. 1180-1183, 1982.

[12] J. L. Ferracane, "Hygroscopic and hydrolytic effects in dental polymer networks," Dental Materials, vol. 22, no. 3, pp. 211-222, 2006.

[13] L. F. J. Schneider, R. R. Moraes, L. M. Cavalcante, M. A. C. Sinhoreti, L. Correr-Sobrinho, and S. Consani, "Cross-link density evaluation through softening tests: effect of ethanol concentration," Dental Materials, vol. 24, no. 2, pp. 199-203, 2008.

[14] N. M. Ayad and H. A. Bahgat, "Comparative evaluation of degree of polymerization and mechanical behavior of three BulkFill composite resins," Egyptian Dental Journal, vol. 61, pp. 4147-4158, 2015.

[15] R. Z. Alshali, N. A. Salim, J. D. Satterthwaite, and N. Silikas, "Post-irradiation hardness development, chemical softening, and thermal stability of bulk-fill and conventional resincomposites," Journal of Dentistry, vol. 43, no. 2, pp. 209-218, 2015.

[16] L. E. Nielsen, "Cross-linking-effect on physical properties of polymers," Journal of Macromolecular Science Part C, vol. 3, no. 1, pp. 69-103, 1969.

[17] J. F. McCabe and A. W. G. Walls, Applied Dental Materials, Blackwell Publishing Ltd, Oxford, UK, 9th edition, 2009.

[18] E. Asmussen and A. Peutzfeldt, "Two-step curing: influence on conversion and softening of a dental polymer," Dental Materials, vol. 19, no. 6, pp. 466-470, 2003.

[19] N. Emami and K.-J. M. Söderholm, "Dynamic mechanical thermal analysis of two light-cured dental composites," Dental Materials, vol. 21, no. 10, pp. 977-983, 2005.

[20] M. S. Soh and A. U. J. Yap, "Influence of curing modes on crosslink density in polymer structures," Journal of Dentistry, vol. 32, no. 4, pp. 321-326, 2004.

[21] H. Burrell, "Solubility parameter values," in Polymer Handbook, J. Brandrup and E. H. Immergut, Eds., pp. 337-359, John Wiley \& Sons, New York, NY, USA, 3rd edition, 1966.

[22] F. Beck, S. Lettner, A. Graf et al., "Survival of direct resin restorations in posterior teeth within a 19-year period (1996-2015): a meta-analysis of prospective studies," Dental Materials, vol. 31, no. 8, pp. 958-985, 2015.

[23] J. L. Ferracane and V. A. Marker, "Solvent degradation and reduced fracture toughness in aged composites," Journal of Dental Research, vol. 71, pp. 13-19, 1992.

[24] H. A. Sunbul, N. Silikas, and D. C. Watts, "Surface and bulk properties of dental resin- composites after solvent storage," Dental Materials, vol. 32, no. 8, pp. 987-997, 2016.

[25] V. E. S. Gajewski, C. S. Pfeifer, N. R. G. Fróes-Salgado, L. C. C. Boaro, and R. R. Braga, "Monomers used in resin composites: degree of conversion, mechanical properties and water sorption/solubility," Brazilian Dental Journal, vol. 23, no. 5, pp. 508-514, 2012.

[26] S. H. Dickens, J. W. Stansbury, K. M. Choi, and C. J. E. Floyd, "Photopolymerization kinetics of methacrylate dental resins," Macromolecules, vol. 36, no. 16, pp. 6043-6053, 2003.

[27] C. S. Pfeifer, L. R. Silva, Y. Kawano, and R. R. Braga, "BisGMA co-polymerizations: influence on conversion, flexural properties, fracture toughness and susceptibility to ethanol degradation of experimental composites," Dental Materials, vol. 25, no. 9, pp. 1136-1141, 2009.
[28] F. Goņalves, Y. Kawano, C. Pfeifer, J. W. Stansbury, and R. R. Braga, "Influence of BisGMA, TEGDMA, and BisEMA contents on viscosity, conversion, and flexural strength of experimental resins and composites," European Journal of Oral Sciences, vol. 117, no. 4, pp. 442-446, 2009.

[29] R. B. Cornelio, A. Wikant, H. Mjosund et al., "The influence of bis-EMA vs bis GMA on the degree of conversion and water susceptibility of experimental composite materials," Acta Odontologica Scandinavica, vol. 72, no. 6, pp. 440-447, 2014.

[30] J. I. Schwartz and K.-J. M. Söderholm, "Effects of filler size, water, and alcohol on hardness and laboratory wear of dental composites," Acta Odontologica Scandinavica, vol. 62, no. 2, pp. 102-106, 2004. 


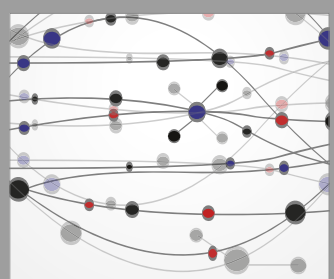

The Scientific World Journal
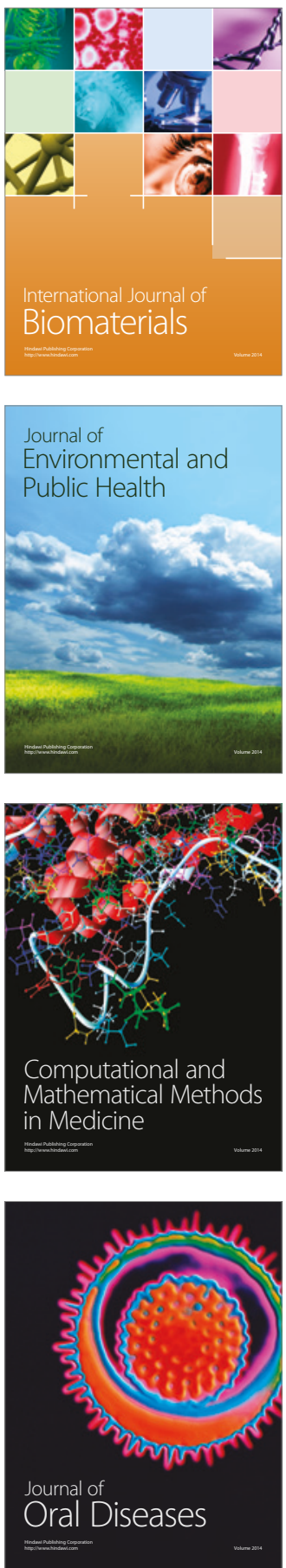
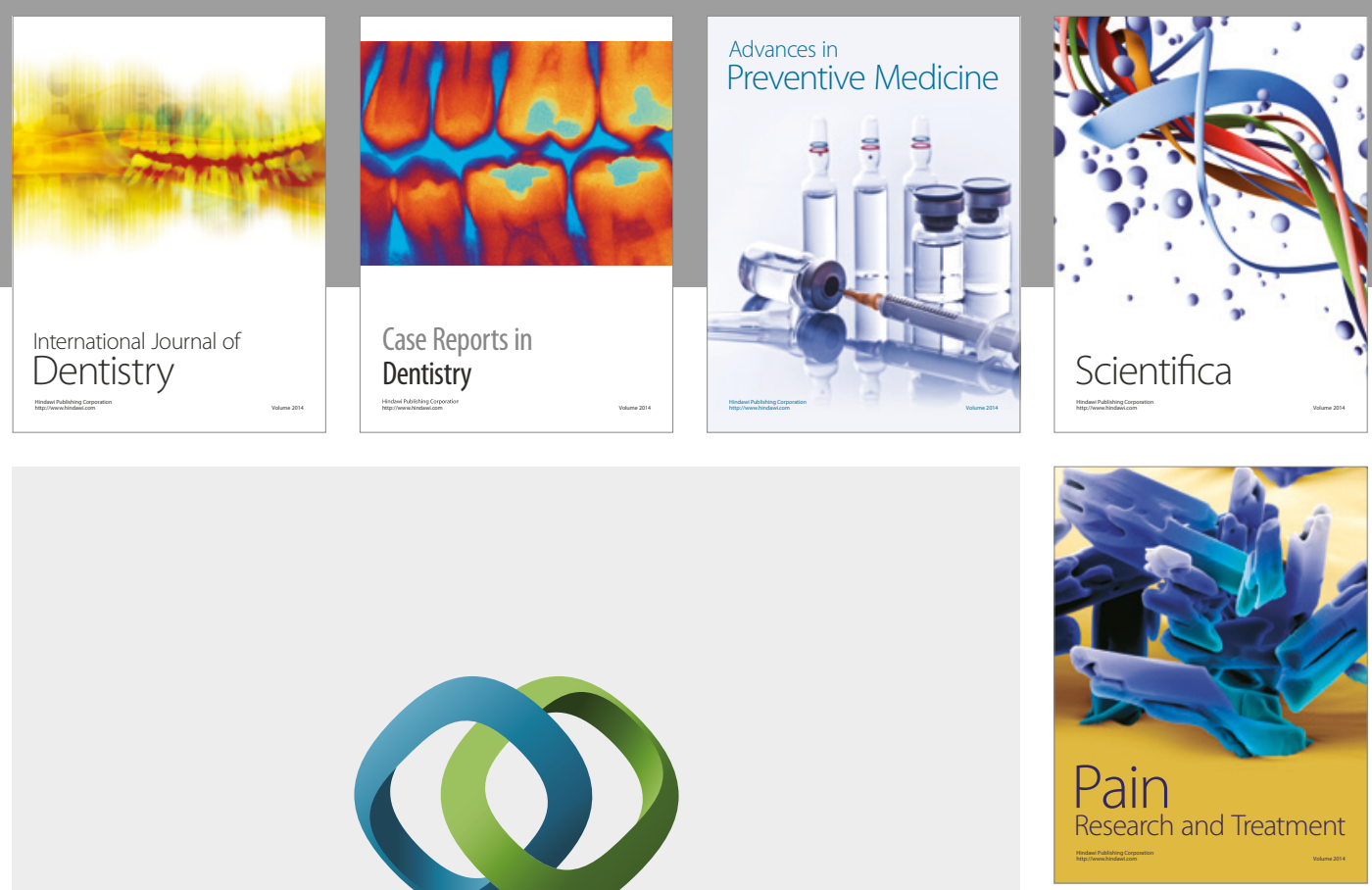

\section{Hindawi}

Submit your manuscripts at

https://www.hindawi.com
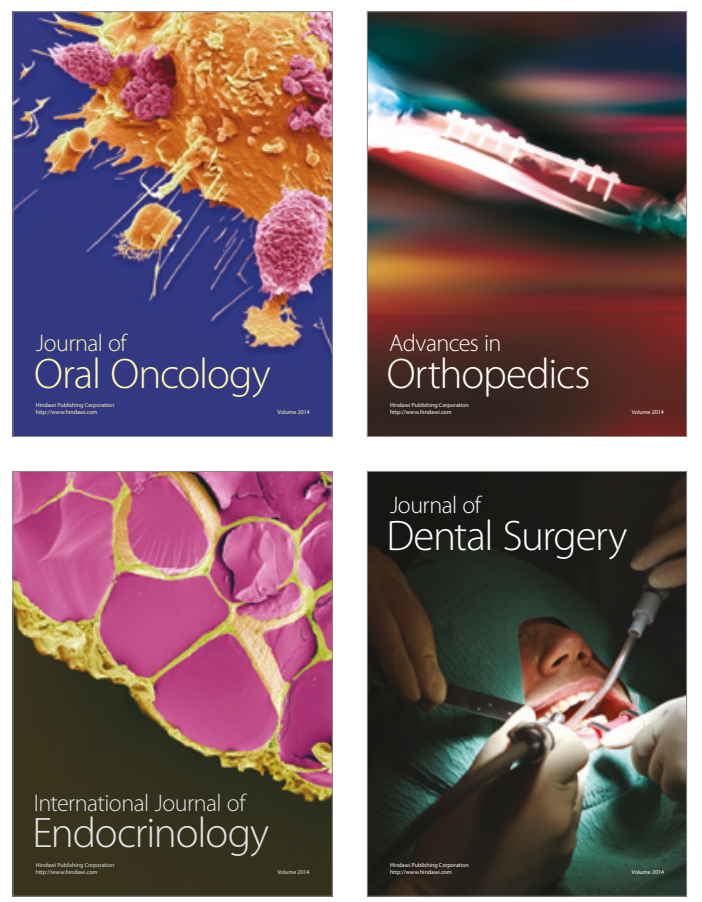
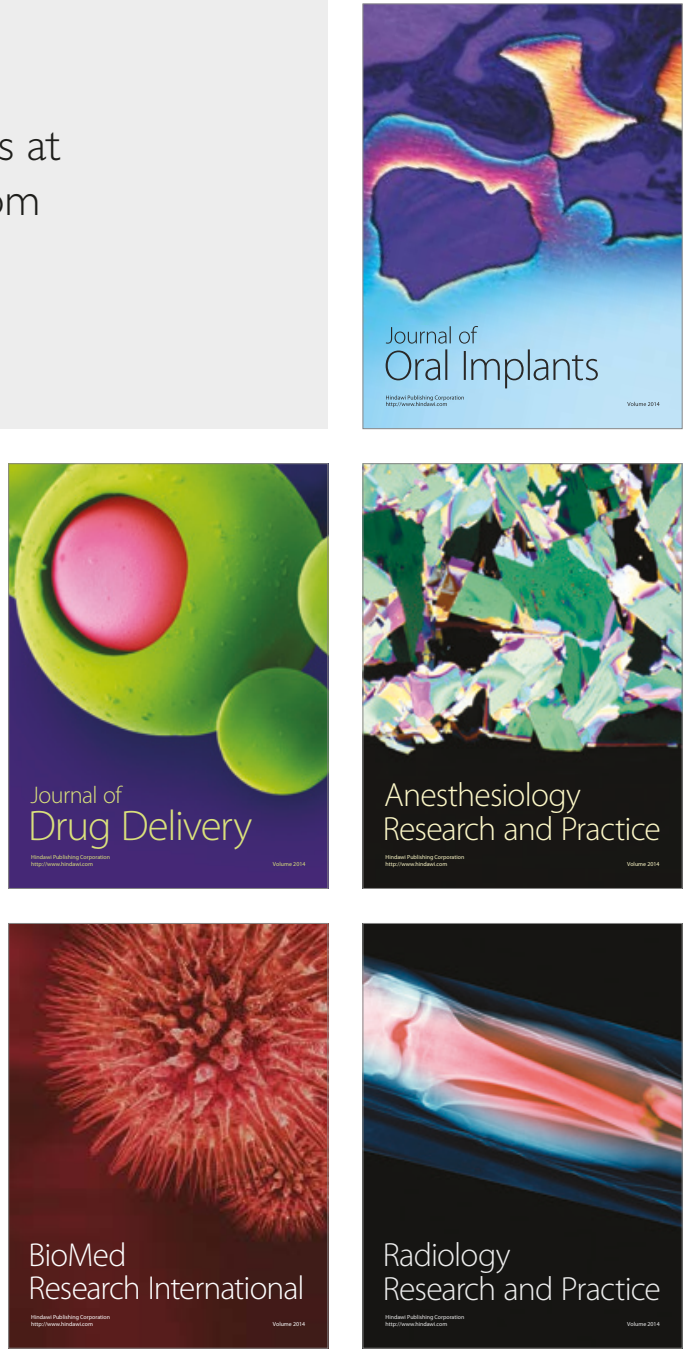